\title{
RAPID ACQUISITION OF BIAS IN SIGNAL DETECTION: DYNAMICS OF EFFECTIVE REINFORCEMENT ALLOCATION
}

\author{
Blake A. Hutsell and Eric A. Jacobs
}

SOUTHERN ILLINOIS UNIVERSITY-CARBONDALE

\begin{abstract}
We investigated changes in bias (preference for one response alternative) in signal detection when relative reinforcer frequency for correct responses varied across sessions. In Experiment 1, 4 rats responded in a two-stimulus, two-response identification procedure employing temporal stimuli (short vs. long houselight presentations). Relative reinforcer frequency varied according to a 31-step pseudorandom binary sequence and stimulus duration difference varied over two values across conditions. In Experiment 2, 3 rats responded in a five-stimulus, two-response classification procedure employing temporal stimuli. Relative reinforcer frequency was varied according to a 36-step pseudorandom ternary sequence. Results of both experiments were analyzed according to a behavioral model of detection. The model was extended to incorporate the effects of current and previous session reinforcer frequency ratios on current-session performance. Similar to findings with concurrent schedules, effects on bias of relative reinforcer frequency were highest for the current session. However, carryover from reinforcer ratios of previous sessions was evident. Generally, the results indicate that bias can come under control of frequent changes in relative reinforcer frequency in both identification and classification procedures.

Key words: acquisition, signal detection, identification, classification, discriminability, temporal discrimination, effective reinforcement, lever press, rats
\end{abstract}

Signal detection procedures allow for the examination of control over behavior by sequential and simultaneous antecedent stimuli and reinforcement variables (Catania, 1998). In a standard two-stimulus, two-response identification task, subjects are presented with one of two possible sample stimuli $\left(\mathrm{S}_{1}\right.$ or $\left.\mathrm{S}_{2}\right)$ on each trial. As shown in Figure 1, either $B_{1}$ or $B_{2}$ responses may be made following either sample stimulus. Matching subscripts within the left matrix (e.g., $\mathrm{B}_{11}$ ) indicate a "correct" (reinforced) response. Each alternative or "error" response $\left(\mathrm{B}_{12}, \mathrm{~B}_{21}\right)$ typically produces a blackout equal to the duration of a reinforcer delivery. In the right

Portions of these data were presented at the 31st and the 32nd annual meetings for the Association for Behavior Analysis-International in Chicago, IL and Phoenix, AZ. The experiments reported here formed part of a doctoral dissertation submitted by the first author to the Graduate School at Southern Illinois University. The authors thank the members of the SIU Operant Lab for helping collect the data and Drs. David Gilbert, Michael May, Matthew Schlesinger, and Michael Young for comments on a previous version of the manuscript. The authors also thank Anthony McLean for his helpful comments on an earlier version of this manuscript. The sequence of reinforcer probabilities can be obtained by contacting the authors.

Address correspondence to Blake Hutsell now at the Department of Psychology, 226 Thach Hall, 342 W. Thach Ave, Auburn University, Auburn, Alabama, 36849-5212 (E-mail: bah0016@auburn.edu). doi: 10.1901/jeab.2012.97-29 matrix of Figure 1 reinforcers for $B_{1} \mid S_{1}$ are designated $R_{11}$ and $B_{2} \mid S_{2}$ reinforcers are designated $R_{22}$.

There are two primary dependent measures in signal detection procedures (for an overview see MacMillan \& Creelman, 1991): the frequency with which subjects respond correctly $\left(B_{11}\right.$ and $\mathrm{B}_{22}$ responses) and the frequency with which subjects make one type of response more frequently than another $\left(B_{i 1}\right.$ relative to $B_{i 2}$ responses). The former is a measure of discrimination, which ostensibly relates to the sensory aspects of the procedure. The latter measure is called response bias and relates to preference-affecting variables such as relative payoffs (e.g., reinforcer rate or magnitude) or information feedback for correct and incorrect responses. A number of theoretical models (see Egan 1975; Green \& Swets, 1966; Luce, 1963) have been advanced to explain changes in discrimination and bias as a function of manipulations in both sensory and preference-affecting variables. The present experiments focus on a reinforcement-based choice model of signal detection performance (Alsop, 1991; Davison, 1991; Davison and Nevin, 1999).

Davison and Nevin (1999) extended an earlier model of signal detection (Alsop \& Davison, 1991; Davison \& Jenkins, 1985) to develop a theory of effective reinforcement. Effective reinforcement, in Davison and Nevin's 


\section{Responses}

\begin{tabular}{|c|c|c|c|c|}
\hline \multirow{3}{*}{ 坓 } & $\mathrm{B}_{1}$ & $\mathrm{~B}_{2}$ & $\mathrm{~B}_{1}$ & $\mathrm{~B}_{2}$ \\
\hline & $B_{11}$ & $B_{12}$ & $R_{11}+\frac{R_{22}}{d_{r} d_{s}}$ & $\frac{R_{11}}{d_{r}}+\frac{R_{22}}{d_{s}}$ \\
\hline & $B_{21}$ & $B_{22}$ & $\frac{R_{11}}{d_{s}}+\frac{R_{22}}{d_{r}}$ & $\frac{R_{11}}{d_{r} d_{s}}+R_{22}$ \\
\hline
\end{tabular}

Fig. 1. Left: The two-stimulus, two-response signal detection matrix. $\mathrm{S}_{i}$ refers to the sample presented on a given trial and $\mathrm{B}_{j}$ refers to frequency of response $\left(B_{i j}\right)$ in the presence of or following $S_{i}$. $R_{i j}$ refers to reinforcer frequencies obtained for correct responses. Right: See text for further details.

account, is an intervening variable representing the sum of direct and generalized reinforcement for a particular response class. Generalized reinforcement is a quantity representing the effects of reinforcers produced by different response classes discounted, or reduced in effect, by the psychophysical distance between the respective stimuli and/or responses present in the environment (see Rachlin, 2006). The Davison and Nevin theory proposes that response allocation in signal detection (and related procedures) strictly matches the effective reinforcer ratio. Thus, Davison and Nevin's theory is consistent with the matching law (Baum \& Rachlin, 1969; Killeen, 1972; Rachlin, 1971), where the transformation of reinforcer dimensions is assumed to result from imperfect discriminative control on one or more dimensions of the concurrent three-term contingencies under investigation. It should also be noted, that according to Davison and Nevin, the terms in the right matrix of Figure 1 represent the accumulated numbers of effective reinforcers over many trials. That is, the steady-state version of the model provides no way of updating effective reinforcer totals based on the occurrence or nonoccurrence of $R_{11}$ or $\mathrm{R}_{22}$ on a single trial. Therefore, in Davison and Nevin's account, derived measures such as discrimination and bias are the result of the long-term accumulation of effective reinforcers for each response alternative.

Specifically, in a standard two-stimulus, tworesponse identification procedure (see Figure 1 ), a reinforcer produced by either $B_{11}$ or $\mathrm{B}_{22}$ will affect all responses in the situation. The effect of the reinforcer on any other response is inversely related to its psychophysical stimulus $\left(d_{\mathrm{s}}\right)$ and response $\left(d_{\mathrm{r}}\right)$ distance from the reinforcer-producing response. The parameters $d_{\mathrm{s}}$ and $d_{\mathrm{r}}$ measure the extent of differential control by the sample stimuli (Alsop \& Davison, 1991) and by response alternatives or comparison stimuli (Godfrey \& Davison, 1999; Nevin, Cate, \& Alsop, 1993), respectively. Following Alsop (1991) and Davison and Nevin (1999), the Davison-Nevin-Alsop model (DNA model hereafter) predicts that in a $2 \times 2$ procedure, as illustrated in the right matrix of Figure 1, reinforcers delivered for correct responses will affect all other responses to the extent that the sample stimuli and response alternatives, respectively, are discriminable. The equation used to predict the ratio of correct to incorrect responses following sample $S_{1}$ is

$$
\left(\frac{B_{11}}{B_{12}}\right)=c\left(\frac{R_{11}^{\prime}}{R_{12}^{\prime}}\right)=c\left(\frac{R_{11}+\frac{R_{22}}{d_{r} d_{s}}}{\frac{R_{11}}{d_{r}}+\frac{R_{22}}{d_{s}}}\right)
$$

and the ratio of incorrect to correct responses following $S_{2}$ is:

$$
\left(\frac{B_{21}}{B_{22}}\right)=c\left(\frac{R_{21}^{\prime}}{R_{22}^{\prime}}\right)=c\left(\frac{\frac{R_{11}}{d_{s}}+\frac{R_{22}}{d_{r}}}{\frac{R_{11}}{d_{r} d_{s}}+R_{22}}\right)
$$

where $\mathrm{B}_{11}$ and $\mathrm{B}_{12}$ are frequencies of correct and error responses following $S_{1}$ and $B_{22}$ and $B_{21}$ are frequencies of correct and error responses following $S_{2}$. The variables $R_{11}$ and $R_{22}$ are the numbers of experimenter-delivered reinforcers for correct responses following $S_{1}$ and $S_{2}$, respectively. The parameters $d_{s}$ and $d_{r}$ are measures of stimulus and contingency discriminability, respectively. Note that the discriminability between a stimulus or response and itself is equal to $1.0\left(d_{s 11}=d_{r 11}=1.0, \mathrm{R}_{11} / d_{s 11} d_{r 11}=\mathrm{R}_{11}\right)$. The constant $c$ is included in Equations 1 and 2 to account for the effects of any constant, unmeasured choice-affecting variables independent of the effective reinforcer ratio. The primed reinforcement variables, $R_{i 1}^{\prime}$ and $R_{i 2}^{\prime}$, represent the effective reinforcement (direct and generalized) for each response. We introduce the primed reinforcer frequency notation here to foreshadow the use of multiple effective reinforcer frequencies in quantitative expressions used to predict behavior in the experiments that follow. 
In their review, Davison and Nevin (1999) showed that the model outlined above accounted for several findings in the signal detection and conditional discrimination literatures. An important question that remains unanswered, however, concerns the time scale at which stimulus and contingency discriminability operate in order to produce an effective reinforcer value for each response alternative. Davison and Nevin suggest that their account is sequential and dynamic, implying a local process (narrow temporal window) by which effective reinforcement is determined. To evaluate this hypothesis will require an analysis of signal detection performance in transition.

Recently, investigations of choice in concurrent schedules have employed novel procedures where relative reinforcement variables transition frequently either within or between sessions (Davison \& Baum, 2000; Hunter \& Davison, 1985; Gallistel, Mark, King, \& Latham, 2001; Mazur, 1992; 1995). Generally, these studies have found that relative response rate can adapt quickly to frequent changes in relative reinforcer frequency. Furthermore, this research has begun to reveal local mechanisms (Davison \& Baum, 2002; 2003; Gallistel et al., 2007; Grace \& McLean, 2006; Krägeloh, Davison, \& Elliffe, 2005) that may give rise to the molar regularities observed in steady-state procedures typically used to study behavior allocation (see Davison \& McCarthy, 1988).

Hunter and Davison (1985) introduced one procedure for investigating preference in transition where relative reinforcement variables changed each session. They found that varying relative reinforcer frequency in a concurrent schedule according to a pseudorandom binary sequence (PRBS) produced rapid changes in preference. They also found that after several sessions of exposure to the PRBS, preference was only sensitive to the current-session reinforcer ratio, with little discernable effects of the previous sessions' reinforcer ratios. Schofield and Davison (1997) replicated and extended these findings to several reinforcer rate ratios and to both dependent and independent concurrent schedules. Schofield and Davison (1997) analyzed their data with an extended generalized matching model proposed by Davison and McCarthy (1988) to describe control over responding by reinforcer ratios in the current and previous nine sessions. They reported that performance in the current session was mostly determined by the current session's reinforcer ratio and to a smaller degree by previous sessions' reinforcer ratios. Schofield and Davison also reported that sensitivity to current-session reinforcer ratios increased with extended exposure to the PRBS procedure. Finally, they reported no effect of the size of reinforcer ratio $(8: 1,4: 1,2: 1,1: 2,1: 4$. $1: 8)$ on estimates of sensitivity to current-session reinforcer rate ratios. Based on these findings, Schofield and Davison argued that the PRBS design was a useful method for rapid determination of sensitivity to reinforcement.

More recently, Grace, Bragason, and McLean (2003) have extended the PRBS design to concurrent-chained schedules of reinforcement. In the first experiment of their study they varied the delay to reinforcement in one terminal link while holding the other reinforcer delay constant. Thus, the immediacy ratio (reciprocal of delay ratio) changed randomly between sessions from 1:2 to 2:1. Grace and colleagues exposed their pigeons to three, 31-session sequences of the PRBS and reported that across sequences, preference came under increasing control of current- session immediacy ratios (see also Grace \& McLean, 2006). Extension of the PRBS design to concurrent chained schedules is important to the present research because it shows that behavior allocation not only adjusts rapidly to frequent changes in primary reinforcer rate ratios, but also (to a lesser extent) to changes in the value of stimuli correlated with primary reinforcement (Grace, 1994; Mazur, 2001, Shahan, Podlesnik, \& Jimenez-Gomez, 2006).

Here we report two experiments mutually inspired by the recent work on choice in transition and the account offered by Davison and Nevin (1999). The present studies sought to extend the PRBS method of varying relative reinforcer frequency to a two-stimulus, tworesponse identification and a five-stimulus, two-response classification procedure, respectively. Specifically, we explored the extent to which the tendency to report one stimulus more frequently than another (i.e., bias) changes within a session when the obtained ratio of reinforcers changes each session.

\section{EXPERIMENT 1}

In Experiment 1, the relative frequency of reinforcement for correct responses in a 2stimulus, two-response detection task employing 
temporal stimuli (short vs. long houselight presentations) was varied according to a 31session PRBS. Across conditions, the difference between the temporal sample stimuli was varied, creating two levels of discrimination difficulty. We asked whether detection performance and specifically bias could come under control of frequent, random changes in the reinforcer ratio for correct responses. Furthermore, we were interested in the extent to which changes in bias depended on the disparity of the sample stimuli.

\section{METHOD}

\section{Subjects}

The subjects were 4 male Long Evans Hooded rats (J85, J86, J87, and J88). All rats were approximately 12 months old and experimentally naïve at the beginning of the experiment. Each rat received $15 \mathrm{~g}$ of chow following each experimental session. The rats were housed individually and had free access to water when in their home cages in a vivarium with a $12: 12 \mathrm{hr}$ light/dark cycle (lights on at 6:00 a.m.). Sessions were conducted daily, at approximately the same time with few exceptions. Experimental sessions were conducted during the rats' light period.

\section{Apparatus}

The experiment was conducted in two standard operant conditioning chambers (Coulbourn Instruments H10-11R-TC) measuring $29 \mathrm{~cm}$ high by $29 \mathrm{~cm}$ wide by $24 \mathrm{~cm}$ deep. Each chamber was enclosed in a soundattenuating cubicle. A white noise generator in the running room masked extraneous sounds.

On the front wall were two identical response levers, one $2.2 \mathrm{~cm}$ from the left wall and the other $2.2 \mathrm{~cm}$ from the right wall, $6 \mathrm{~cm}$ above the grid floor. The levers were $3.5 \mathrm{~cm}$ across and extended $2 \mathrm{~cm}$ into the chamber. A downward force on the lever of at least $0.3 \mathrm{~N}$ operated a switch that was connected to the lever and thereby generated a recordable response. Three small lights arranged in a horizontal row $3.5 \mathrm{~cm}$ apart center to center were located $2.5 \mathrm{~cm}$ above each lever. Only the center lights were used in the current experiment. In the first chamber, the light above the left lever was illuminated white and the light above the right lever was illuminated blue. In the second chamber, the light above the left lever was illuminated red and the light above the right lever green. Experimental sessions were conducted in the first chamber for rats J85 and J86 and in the second for rats J87 and J88. Located centrally at the top of the intelligence panel was a house light that served to present sample stimuli.

Centered on the front wall, $1.5 \mathrm{~cm}$ above the floor, was a rectangular opening $(4.1 \mathrm{~cm}$ high and $6.3 \mathrm{~cm}$ wide) through which the rat could obtain the reinforcer (sweetened condensed milk). The liquid dipper (Colbourn Instruments H14-06R) normally rested in a reservoir outside the chamber. The size of the dipper cup was $0.05 \mathrm{ml}$. The milk solution was one part milk and three parts tap water.

All experimental events were written and compiled in Quick Basic ${ }^{\circledR}$ programming language. For each chamber a digital I/O card (Computer Boards, Inc. Model \# CIO-PDISO16) interfaced to an IBM-compatible computer (located in an adjacent room) that controlled all experimental events and recorded data.

\section{Procedure}

Preliminary training. Initially, left and right lever pressing was established via autoshaping. Once lever pressing was established, the rats were exposed to the basic temporal discrimination procedure. Initially, each rat was trained on a procedure in which correct responses following short and long sample stimuli were reinforced continuously (FR1). Each right lever press following a 2-s houselight presentation and each left lever press following an 8-s houselight presentation was reinforced. Training sessions involved 150 discrete trials, each beginning with the sample stimulus. Upon termination of the houselight, the lights above each lever were illuminated and trials ended after either a lever press or $5 \mathrm{~s}$, whichever occurred first. Each sample stimulus was presented 75 times in each session and stimulus presentation was randomized every block of 30 trials. Correct responses were reinforced with two 2-s milk deliveries, $0.5 \mathrm{~s}$ apart, followed by the intertrial interval (ITI) and incorrect responses led directly to the ITI. During the ITI all stimulus lights were turned off for $15 \mathrm{~s}$ and no consequences were arranged for lever pressing.

Preliminary training lasted approximately 50 sessions. During these sessions, the overall probability of reinforcement for correct responses was gradually decreased to 0.70 . As reinforcement density decreased, reinforcers were arranged dependently (Stubbs \& Pliskoff, 1969) such that a reinforcer assigned to a 
particular correct response was held and no other response could be reinforced until that reinforcer was obtained. Correct responses that were not eligible for reinforcement, and incorrect responses, led directly to the ITI.

PRBS conditions. When accuracy on the 2versus 8-s duration discrimination reached a steady state, as judged by visual inspection of measures of response bias and discrimination accuracy (see below), rats were exposed to the first PRBS condition. With the exception of the PRBS, procedures in these conditions were unchanged from those used in the terminal preliminary training sessions. The PRBS arranged for reinforcement of correct short responses at a probability of either 0.75 or 0.25 within a given session. The probability of reinforcement for correct long responses was the complement of the above probabilities.

After the 31 sessions under the first PRBS, rats were returned to equal reinforcer probability training and the sample durations were changed to 3 and $5.5 \mathrm{~s}$. The relation between right-left lever presses identified as correct, or incorrect responses and short-long stimulus presentations remained constant. Once response bias and discrimination accuracy reached steady state at these durations, rats were again exposed to a 31session PRBS with the same reinforcement probabilities as noted above. Three of the four rats were then exposed to a third 31-session PRBS condition. Again, each rat was returned briefly to the final preliminary training conditions with equal reinforcement probabilities. Rats J85 and J86 completed a replication of the 2- versus 8-s sample stimulus condition, and J88 was exposed to a replication of the 3-versus 5.5-s stimulus. Rat J88 died shortly after completion of the second PRBS.

\section{Results And Discussion}

First, to demonstrate that the different stimulus conditions produced different levels of accuracy, Figure 2 shows accuracy expressed as $\log D$ (Davison \& Tustin, 1978). To display discrimination performance for each condition simultaneously, the data plotted in Figure 2 are from the final five sessions at each relative reinforcer probability for each PRBS condition. Stimulus discriminability $(\log D)$ is calculated as:

$$
\log D=0.5 \cdot \log \left(\frac{B_{11}}{B_{12}} \cdot \frac{B_{22}}{B_{21}}\right)
$$

where $B_{i j}$ refers to the frequency of response in the different cells of the matrix of Figure 1. This measure of discrimination performance is the geometric mean of the logarithm (base 10) of the ratio of correct to error responses and indicates the overall tendency for a rat to make a correct response independent of the reinforcer ratio (Davison \& Tustin, 1978). Figure 2 shows that the different pairs of sample stimulus durations produced changes in the propensity to make a correct response. Note that $\log D$ is not plotted for sessions where rats made zero errors (this occurred in two sessions for one rat, J85, following presentation of the 2-s stimulus).

Overall, changes in relative reinforcer probability for correct responses arranged according to the PRBS produced between-session changes in response bias, $\log B$ (Davison \& Tustin, 1978). Figure 3 shows response bias plotted as a function of PRBS session. Bias (log $B)$ is calculated as:

$$
\log B=0.5 \cdot \log \left(\frac{B_{11}}{B_{12}} \cdot \frac{B_{21}}{B_{22}}\right)
$$

where $B_{i j}$ refers to the frequency of response in the different cells of the matrix of Figure 1. This measure of bias is the geometric mean of the logarithm (base 10) of the ratio of right and left responses and indicates the overall tendency for a rat to make a right $\left(B_{1}\right)$ or left $\left(B_{2}\right)$ lever press (Davison \& Tustin, 1978). Each data point in Figure 3 represents performance in a single session. As above, $\log B$ is not plotted for sessions in which zero errors occurred. Inspection of Figure 3 reveals that bias tracked changes in the reinforcer frequency ratio. Individual differences in performance are also readily apparent. One rat, J85, showed an overall tendency to respond more on the right lever $\left(B_{1}\right)$ regardless of the relative frequency of reinforcement or stimulus conditions. The performance of rat J86 showed greater control by the changing reinforcer ratios than that of the other rats. Levels of response bias for rats J87 and J88 were intermediate.

Previous studies employing the PRBS design have sought to quantify the extent to which performance in a given session is determined by the current reinforcer ratio and the reinforcer ratios in previous sessions (Davison \& McCarthy, 1988; Grace, Bragason, \& McLean, 2003; Schofield \& Davison, 1997). These analyses have been based on a generalized 


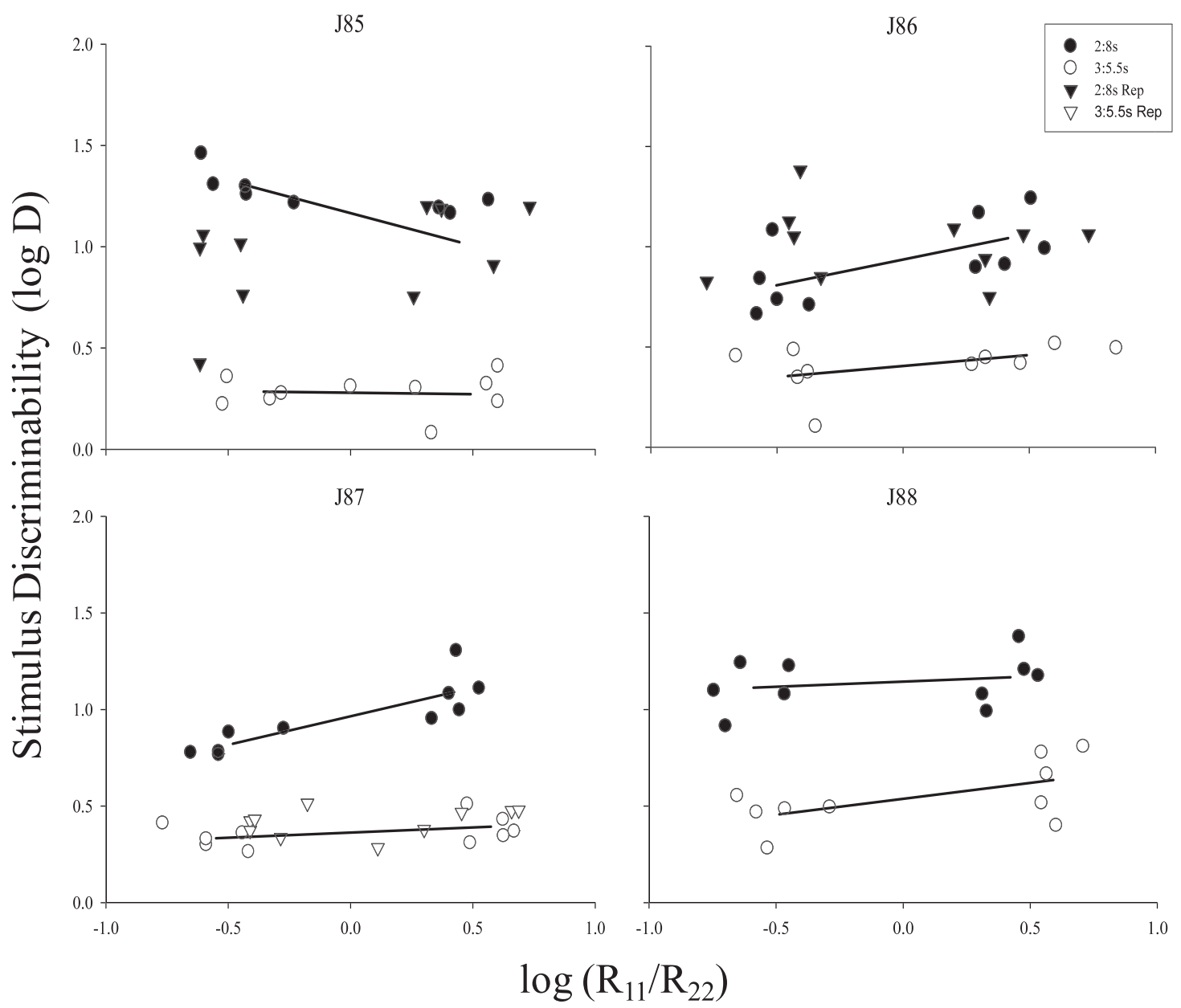

Fig. 2. Stimulus discriminability expressed as $\log \mathrm{D}$ (Eq. 3) as a function of obtained sessional reinforcer ratio. Estimates of $\log \mathrm{D}$ are presented for each subject for the last 10 sessions at each reinforcer ratio for each condition of Experiment 1. Lines connect estimates of the same measures based on sums of responses and reinforcers across sessions.

matching model where performance in the current session is predicted by including the current and previous sessions' reinforcer ratios. Such an analysis of the current data set requires extension of the DNA model (Alsop, 1991; Davison; 1991; Davison \& Nevin, 1999) to include reinforcer ratios from prior sessions. The reinforcer matrix in Figure 1 gives the effective reinforcer terms used to predict detection performance according to the model. The notation used to describe the effective reinforcer frequency in each cell of the matrix is $R_{i j}^{\prime}$, where $i j$ corresponds to the cells of the 2 $\times 2$ matrix. The present analysis extended the model by using the current and previous three sessions' reinforcer ratios to predict currentsession performance, as previous studies have shown little effect of greater lags (Grace, Bragason, \& McLean, 2003; Kyonka \& Grace, 2008; Schofield \& Davison, 1997). We employed perhaps the simplest extension of the model, assuming an additive effect of current and previous sessions' effective log reinforcer ratios on current-session performance. This model is written:

$$
\begin{aligned}
\log \left(\frac{B_{i 1}}{B_{i 2}}\right)= & \log \left(\frac{R_{i 1 n}^{\prime}}{R_{i 2 n}^{\prime}}\right)+\log \left(\frac{R_{i 1(n-1)}^{\prime}}{R_{i 2(n-1)}^{\prime}}\right) \\
& +\log \left(\frac{R_{i 1(n-2)}^{\prime}}{R_{i 2(n-2)}^{\prime}}\right)+\log \left(\frac{R_{i 1(n-3)}^{\prime}}{R_{i 2(n-3)}^{\prime}}\right) \\
& +\log c
\end{aligned}
$$




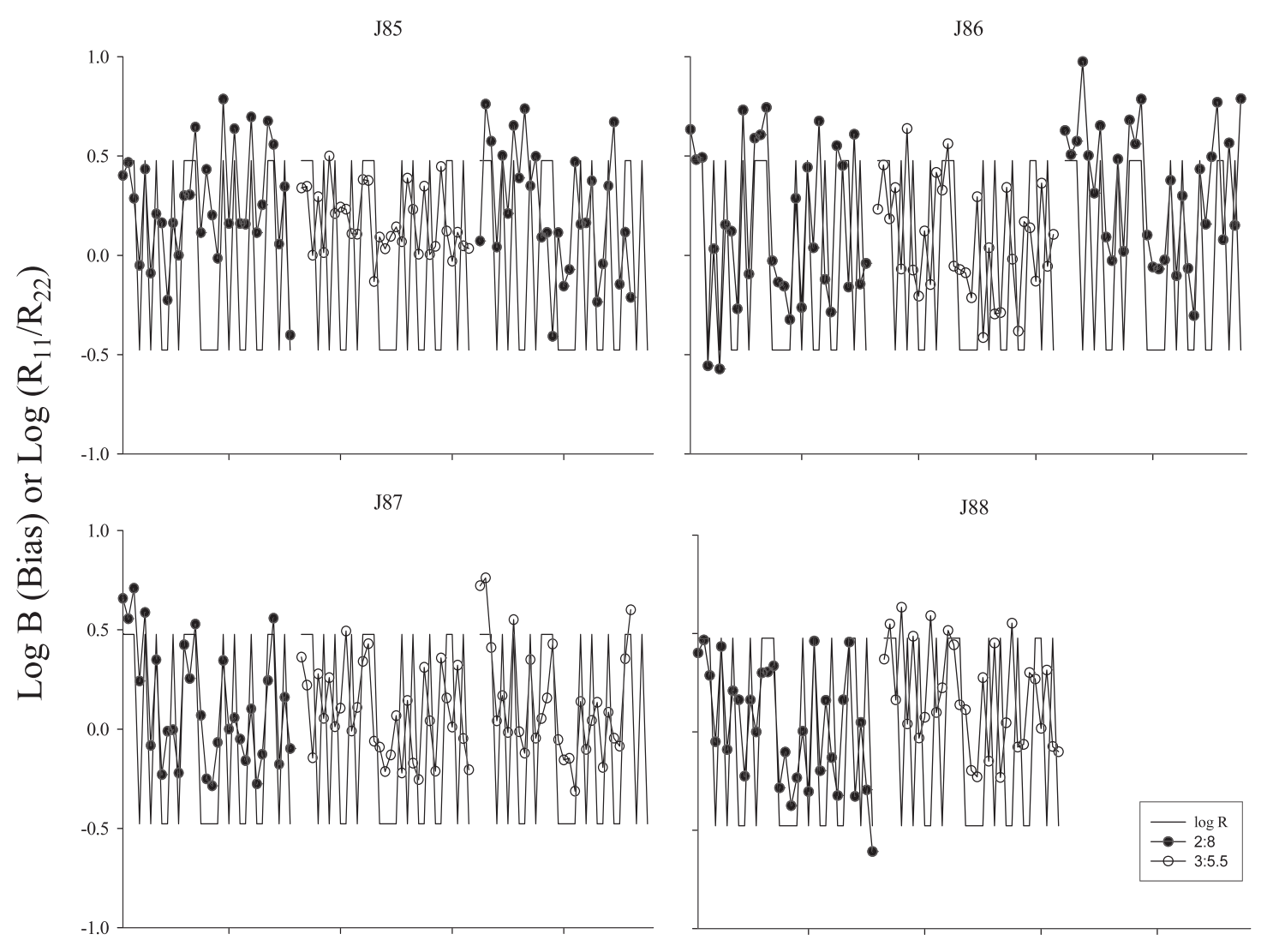

\section{Sessions}

Fig. 3. Response bias (heavy lines, filled symbols), expressed as $\log \mathrm{B}$ (Eq. 4), and the $\log \mathrm{R}\left(\mathrm{R}_{11} / \mathrm{R}_{22}\right)$, the reinforcer frequency ratio (light lines) as a function of session number for PRBS presentations completed by each subject. To avoid overlap, successive PRBS presentations have been separated by one session. See text for further explanation of individual subject condition order.

where $\mathrm{B}_{i 1}, \mathrm{~B}_{i 2}, \mathrm{R}^{\prime}{ }_{i 1}$, and $\mathrm{R}^{\prime}{ }_{i 2}$ refer to the right and left response frequencies and effective reinforcer frequencies following $S_{1}$ and $S_{2}$ presentations, respectively. Reinforcer frequencies are subscripted by $n$ for the current session, $n-1$ for the previous session, and so on. In Equation 5 the parameter $\log c$ represents a constant bias towards one response that is independent of changes in the effective reinforcer frequency ratio. Equation 5 was applied to the $\log$ response ratios obtained from sessions 4-31 of each PRBS presentation. Because variables that ought to affect discriminability were held constant within a PRBS presentation, a more succinct presentation of the dynamics of response bias in response to daily changes in the programmed log reinforcer ratio may be achieved by using estimates of contingency discriminability as a proxy for response bias in the present experiments. Thus, each fit required one $d_{s}$ parameter, one $\log c$ parameter, and four $d_{r(n-i)}$ parameters measuring the contributions of the current and each of the three previous sessions' reinforcer ratios $(i=0-3)$ to current-session performance. Equation 5 was fitted to the $\log$ response ratios following each stimulus $\left(\mathrm{S}_{1}\right.$ and $\left.\mathrm{S}_{2}\right)$ simultaneously by nonlinear least squares regression using the Solver tool in Microsoft ${ }^{\circledR}$ Excel. It may be instructive to make explicit that the model proposed in Equation 5 is an attempt to predict the measure of bias expressed in Equation 4 and shown graphically in Figure 3. That is, separate versions of Equation 5 for performance following $S_{1}$ and $S_{2}$ can be used to predict measures of bias such as $\log B$.

It is important to note that when $d_{r(n-i)}$ is equal to 1.0, experimenter-delivered reinforcers 


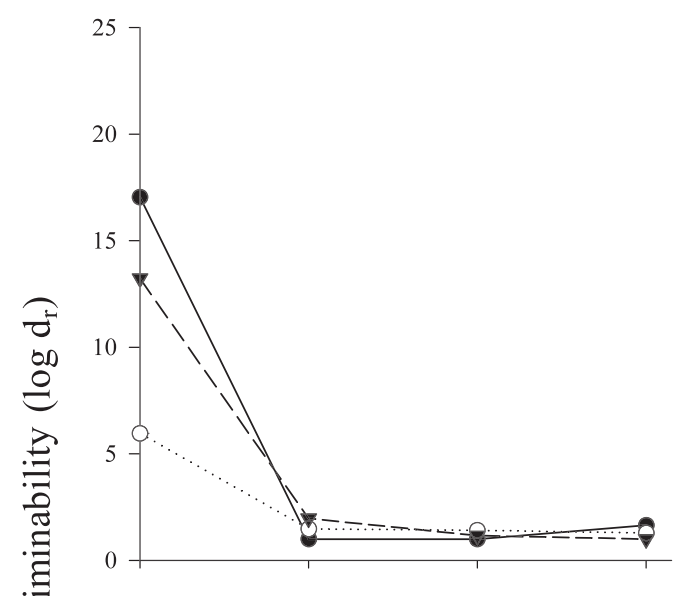

J87

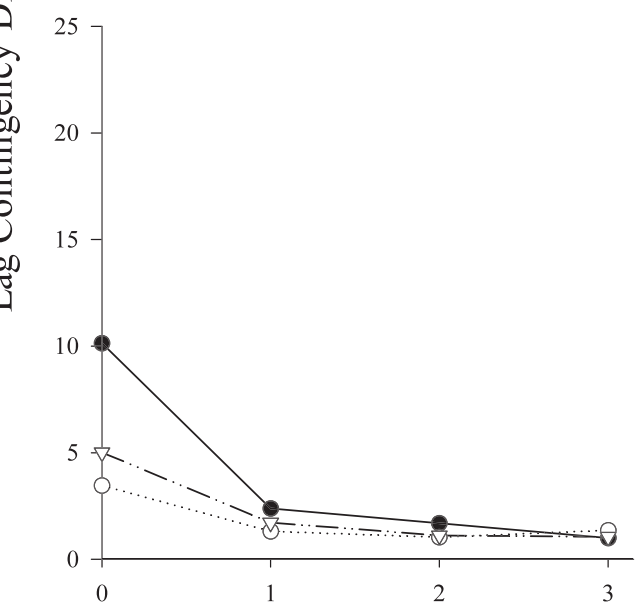

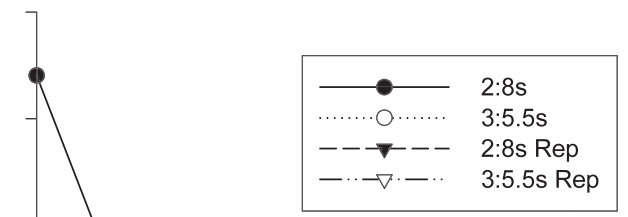

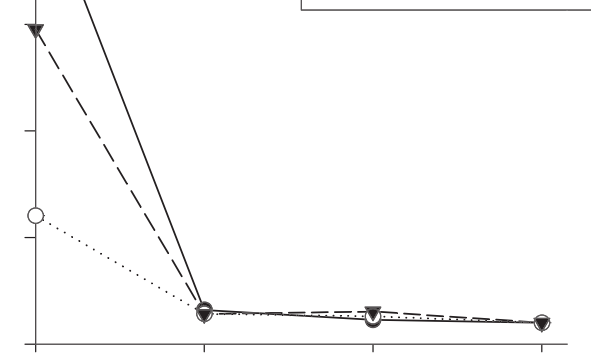

J88

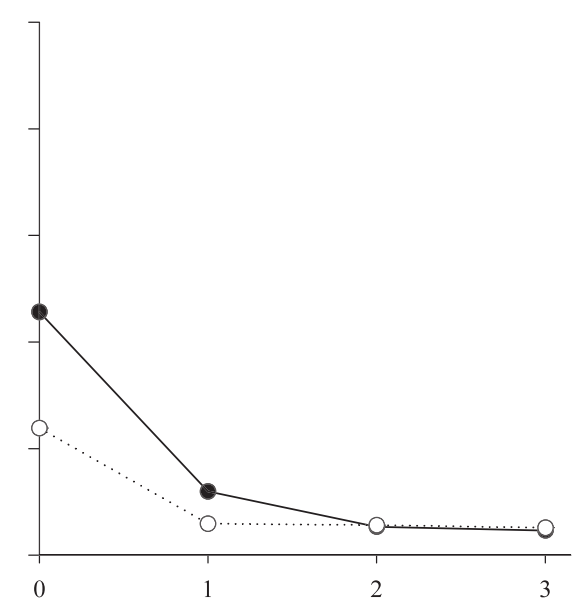

Lag (Sessions)

Fig. 4. Contingency discriminability estimates based upon the current and previous session reinforcer ratios for each PRBS presentation of Experiment 1. The legend indicates the PRBS presentation from which the $\mathrm{d}_{r}$ estimate was obtained. The dotted lines across the bottom of the graphs show the lower limit of the parameter value. Conditions are labeled according to sample stimulus durations, $\mathrm{R}$ indicates a replication.

are nondifferentiable (i.e., complete induction) with respect to $B_{i 1}$ and $B_{i 2}$. Therefore, the ratio of effective reinforcers is equal to 1.0 and hence the logarithm of the effective reinforcer ratio is equal to zero, and there can be no differential effects of the reinforcer ratio on responding irrespective of obtained stimulus discriminability. Because the DNA model assumes strict matching of $\log$ response ratios to log effective reinforcer ratios, as contingency discriminability $d_{r}$ increases, the log response ratio and hence bias will more closely match the log obtained reinforcer ratio.

Figure 4 shows contingency discriminability $\left(d_{r}\right)$ estimates for each session lag and each PRBS presentation obtained from fits of Equation 5. In general, Equation 5 provided an excellent description of the data, on average accounting for $93 \%$ of the variance (all \%VAC $>0.87$ ) in the log response ratios across rats and conditions. Contingency discriminability for the current session (lag 0) 
reinforcer ratio was highest and previoussession reinforcer ratios had little effect on performance. For all rats, contingency discriminability was higher when sample stimulus discriminability was highest. That is, behavior came under greater control of the currentsession reinforcer frequency ratio when discrimination accuracy was higher (Figure 2). When rats J85 and J86 were returned to the easier discrimination (2:8-s stimulus presentations), lag 0 contingency discriminability increased, albeit to lower levels than the first PRBS presentation. For rat J87 the PRBS replication of the more difficult discrimination (3:5.5-s stimulus presentations) produced slightly higher estimates of lag 0 contingency discriminability.

Although the previous analysis showed that behavior in a given session was largely under control of that session's reinforcer ratio, it is likely that the previous session's reinforcer ratio had some effect at the beginning of the current session. Therefore, we sought to assess control over current-session performance by current and past reinforcer ratios by estimating values of contingency discriminability $\left(d_{\mathrm{r}}\right)$ within an experimental session. We performed an analysis similar to the session-aggregate lag contingency discriminability analyses on the withinsession data. For the within-session analyses, however, $\log$ response ratios were calculated over five 30-trial blocks and regressions were carried out using the current and immediately prior sessions' programmed reinforcer ratio to predict performance in each fifth of the current session (see Davison \& Baum, 2000; Grace, Bragason, \& McLean, 2003). Equations similar to Equation 5 were fitted simultaneously to $\log$ behavior ratios following $S_{1}$ and $S_{2}$, respectively, for each session fifth using the programmed reinforcer ratios from the previous and current sessions. Data from each session of the first and second PRBS were used to estimate the model parameters. Each fit required a fixed $d_{\mathrm{s}}$ and $\log$ $c$ parameter and a contingency discriminability $\left(d_{\mathrm{r}(\mathrm{n})}\right.$ and $\left.d_{\mathrm{r}(\mathrm{n}-1)}\right)$ parameter estimated for each block, representing the within-session adjustment to the current reinforcer ratio. The results of the within-session changes in contingency discriminability are displayed for the first and second PRBS exposures separately in Figures 5 and 6.

Figure 5 shows that in the first PRBS (2:8 s), where the $S_{1}-S_{2}$ difference was greater, control by the current-session reinforcer ratio was acquired rapidly during sessions, with little discernable effect of the previous sessions' reinforcer ratio by the end of the session. An effect of the previous sessions' reinforcer ratio is evident in the first session fifth. Beyond that point, however, the previous sessions' reinforcer ratio had diminishing effects, as evidenced by $d_{\mathrm{r}}$ values of approximately 1.0 , the minimum value of this parameter. Greater control by the current session's reinforcer ratio was apparent within the first session fifth as evidenced by $d_{\mathrm{r}}$ values above 1.0. Estimates of current-session contingency discriminability continued to increase throughout the session and appeared to stabilize for each rat about midway through the session. Finally, the regression fits from which the $d_{\mathrm{r}}$ estimates in Figure 5 are based were quite good (all VAC $>$ $0.90)$.

Figure 6 shows the results of the withinsession analyses for the second PRBS, in which the sample stimuli were 3 and 5.5 s. Overall, accuracy was lower in the second PRBS (Figure 2). The regressions carried out on the data from the second PRBS also accounted for a lower percentage of variance (mean VAC $=0.66)$. The deviations from predicted response ratios, however, were not systematic. Regressions conducted on the obtained versus predicted data from each rat gave slopes and $y$ intercepts not appreciably different from 1.0 and 0 , respectively. Inspection of Figure 6 shows that estimates of within-session contingency discriminability were much lower in the second PRBS, where the difference in sample stimulus duration was only $2.5 \mathrm{~s}$ (see Figs. 3 \& 4). More notable was the finding that for each rat the estimates of contingency discriminability for the previous session remained above 1.0 throughout most of the session for most of the rats. Furthermore, control by the previous session's reinforcer ratio was sometimes equal to or greater than control by the current session's reinforcer ratio. This relationship is especially apparent in the parameter estimates obtained from J85. For this rat, control over response allocation seemingly switched approximately midway through a session from the current to previous sessions' reinforcer ratio, often producing indifference between the response alternatives (Figure 3).

In summary, the results of Experiment 1 demonstrate that response bias $(\log B)$ in a 
J85

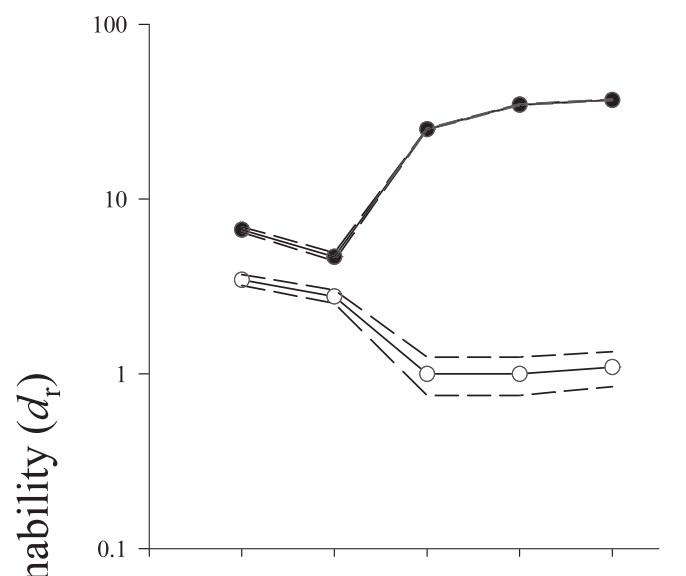

J87

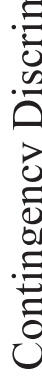

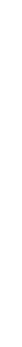

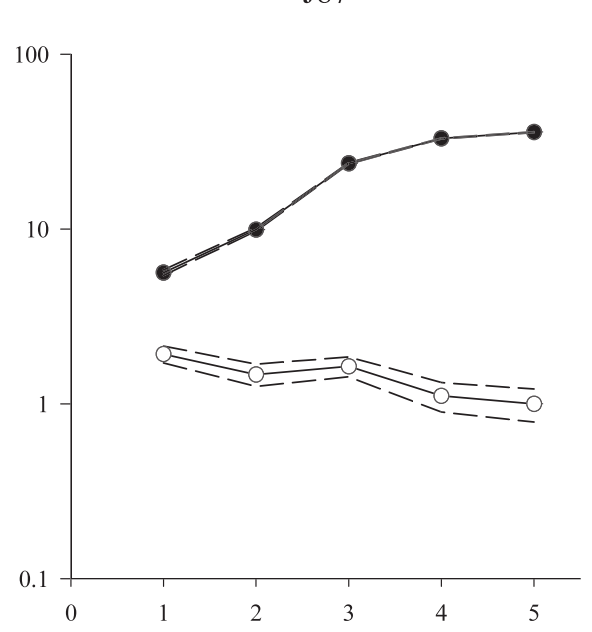

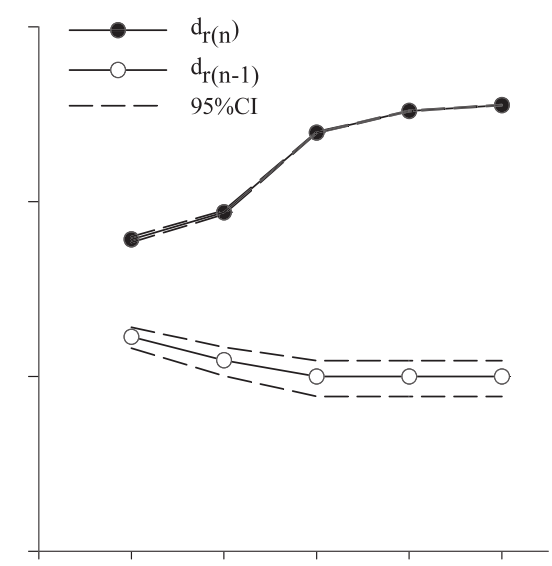

J88

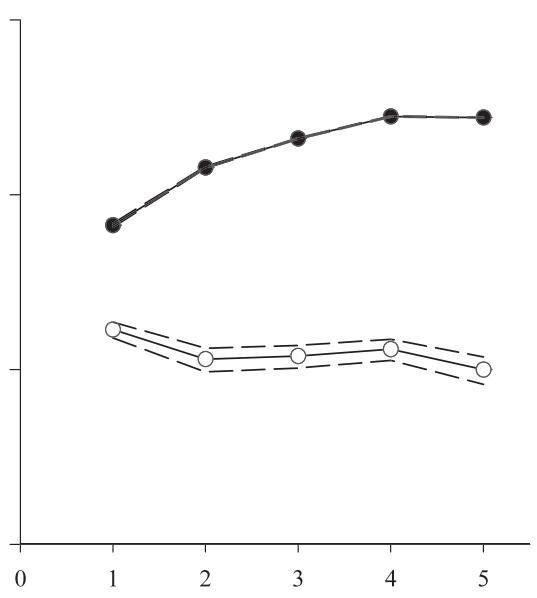

\section{Session Fifth}

Fig. 5. Contingency discriminability $d_{\mathrm{r}}$ obtained for lags 0 through lobtained for each session fifth (30 trials). Data are from the first PRBS with 2- and 8-s sample stimuli of Experiment 1.

signal detection task can change rapidly when the relative frequency of reinforcement changes between sessions. An extended form of the DNA model provided an accurate description of the effects of current- and previous-session reinforcer ratios on current-session performance. In the first PRBS condition, with large differences in the temporal durations defining $S_{1}$ and $S_{2}$, bias changed rapidly within sessions. Estimates of contingency discriminability, obtained from the session aggregate data, were greatest at lag 0 and response bias was largely unaffected by previous sessions' reinforcer ratios. In the second PRBS condition, the $S_{1}$ and $\mathrm{S}_{2}$ stimulus durations were changed such that accuracy, measured as $\log D$, was lower (Figure 2). Under lower levels of discrimination accuracy, variation of the reinforcer ratio had a smaller effect on bias. Contingency discriminability at the session aggregate level, however, was highest at lag 0. Estimates of contingency discriminability based on withinsession data increased throughout the session in the first PRBS exposure (easy discrimination). During the second condition with the more difficult discrimination, estimates of the effects of the current session's reinforcer ratio were low and were sometimes surpassed by the 
J85

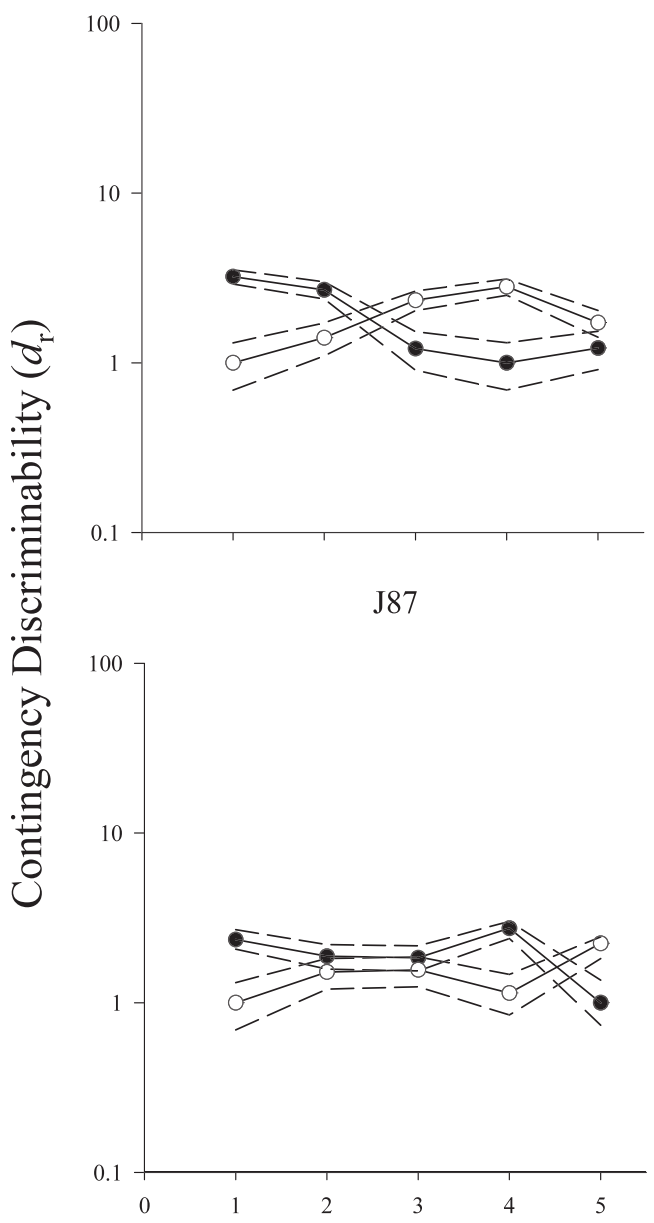

J86
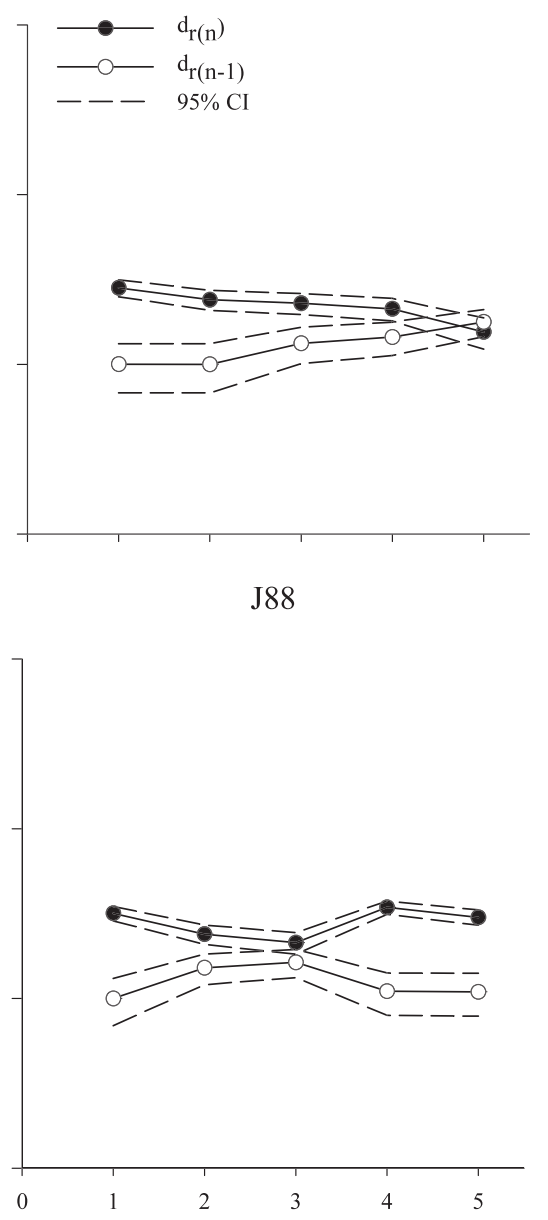

Session Fifth

Fig. 6. Contingency discriminability $d_{\mathrm{r}}$ obtained for lags 0 through 1 obtained for each session fifth (30 trials). Data are from the second PRBS with 3- and 5.5-s sample stimuli of Experiment 1.

effects of previous sessions' reinforcer ratios. We discuss this finding further and attempt to relate it to the findings of previous studies in the General Discussion.

\section{EXPERIMENT 2}

In Experiment 2, the relative probability of reinforcement for correct responses was varied in a 5-stimulus detection task according to a random sequence as in Experiment 1. We were interested in whether response bias would adapt to daily changes in the reinforcer ratio as rapidly in a five-stimulus procedure as in the presumably simpler two-stimulus task. Further- more, we sought to extend Davison's (1991; see also Davison \& Nevin, 1999) $n$-stimulus model of detection to quantify the extent of carryover from previous sessions' reinforcer ratios. In addition, one of the sample stimuli presented each session was never followed by food presentation regardless of which response was made; analogous to a maintained generalization procedure (Blough, 1969). We asked whether performance following this stimulus (technically an $\mathrm{S}^{\Delta}$ ) was biased towards the higher reinforcer probability response alternative in a manner similar to responding that actually produced reinforcer deliveries. If so, this would provide some support for 
Davison and Nevin's conception of effective reinforcement.

\section{MethoD}

\section{Subjects}

The subjects were 3, approximately 12month-old, female Long Evans Hooded rats (J93, J94, and J99). Rats J94 and J99 had prior experience with a free-operant temporal discrimination procedure. Rat J93 had brief exposure to another procedure, but had no prior history of lever pressing. Each rat received $12 \mathrm{~g}$ of chow following each experimental session. The rats' housing conditions, access to water, and light/dark schedule were as in Experiment 1. Sessions were conducted daily, at approximately the same time.

\section{Apparatus}

Chambers were the same as the second chamber described in Experiment 1.

\section{Procedure}

Preliminary training. For J93, lever pressing was shaped by the method of successive approximation. Subsequently, all rats were placed on a concurrent random-ratio (RR), RR schedule of reinforcement. Reinforcers were assigned according to a dependent schedule (Stubbs \& Pliskoff, 1969) such that in the event that a reinforcer was assigned to one response alternative, no other reinforcer could be assigned until the previously allocated reinforcer was obtained. Rats were exposed to this procedure for approximately four weeks and the ratio requirements for both levers were increased to a terminal value of RR 3 .

Subsequently, each rat was exposed to the basic temporal discrimination procedure. On each trial, the houselight was illuminated for one of five durations $(2,3.5,4.5,5.5$, or $8 \mathrm{~s})$. Following the sample stimulus presentation, the lights above each lever were illuminated and trials ended after either a lever press or $5 \mathrm{~s}$, whichever occurred first. Responses to the right lever were reinforced following sample durations of 2 and $3.5 \mathrm{~s}$ and responses to the left lever were reinforced following sample durations of 5.5 and $8 \mathrm{~s}$. Lever presses following a 4.5-s sample presentation were never reinforced. Initially, each correct response was followed by two 2-s presentations of the dipper, with a 0.5-s delay between the presentations. Incorrect responses led directly to the ITI in which all lights in the chamber were extinguished for $7 \mathrm{~s}$. Each session consisted of 200 trials, with 40 presentations of each sample.

Following approximately 30 sessions, the overall density of reinforcement was decreased by implementing a dependent schedule of reinforcement. The dependent schedule or controlled reinforcer ratio procedure (McCarthy \& Davison, 1984) ensured an approximately equal number of reinforcers were obtained for responding to both correct response alternatives. No attempt to equate the number of reinforcers obtained within a stimulus class (2.0-3.5 and $5.5-8.0 \mathrm{~s})$ was made. Upon transition to the dependent schedule, correct responses that were not eligible for reinforcement had the same consequences as error responses (7-s ITI) and correct responses that were eligible for reinforcement continued to produce two dipper presentations. This training phase continued for each rat until the percentage of correct responses following each stimulus was deemed stable by visual inspection of the data. For J94 and J99 training was deemed complete after 45 sessions and for J93 after 80 sessions.

Upon completion of training on the dependent-schedule phase, each rat was exposed to a procedure in which the relative probabilities of reinforcement changed each session. The relative probability of reinforcement for correct responses following either of the shorter stimulus durations was $0.25,0.5$, or 0.75 . This pseudorandom ternary sequence (PRTS) lasted for a total of 36 sessions; each reinforcer probability was allowed to occur three times in each block of nine sessions. The order of reinforcer probabilities was determined separately for each of the four blocks of nine sessions according to the random number generator tool in Microsoft ${ }^{\odot}$ Excel. Each rat was exposed to the 36-session PRTS three times.

\section{Results And Discussion}

As in Experiment 1 and previous studies employing the PRBS design (cf. Schofield \& Davison, 1997), it is important to quantify the extent of control by the present and past reinforcer frequency ratios on current session performance. The data from Experiment 2 can be fitted by Equation 5 above, but require the addition of a stimulus discriminability $\left(d_{\mathrm{sij}}\right)$ 
estimate for each pair of sample stimuli. Following Davison and Nevin (1999), we fitted Equation 5 to the present data with four stimulus discriminability parameters for each adjacent pair of stimuli: $d_{\mathrm{s} 12}, d_{\mathrm{s} 23}, d_{\mathrm{s} 34}$, and $d_{\mathrm{s} 45}$. Estimates of $d_{\mathrm{sij}}$ for all other combinations of stimuli were obtained by multiplying the above estimates, so that for example, $d_{\mathrm{s} 14}$ is the product of $d_{\mathrm{s} 12}, d_{\mathrm{s} 23}$, and $d_{\mathrm{s} 34}$ (see also, Davison \& Nevin, 1999; Krägeloh, Elliffe, \& Davison, 2006). A matrix of the summed reinforcer frequencies divided by the appropriate discriminability parameters was created for each session giving the effective reinforcer frequency for each response alternative. The logarithm of the ratio of the effective reinforcer frequencies was used to predict the logarithm of the response ratios following each stimulus. For example, following sample $S_{3}$, the effective reinforcer frequency for each response is:

$$
\begin{aligned}
R_{31}^{\prime}= & \frac{R_{11}}{d_{s 13}}+\frac{R_{21}}{d_{s 23}}+\frac{R_{31}}{d_{s 33}} \\
& +\frac{R_{32}}{d_{r 12}}+\frac{R_{42}}{d_{s 34} d_{r 12}}+\frac{R_{52}}{d_{s 35} d_{r 12}}
\end{aligned}
$$

and

$$
\begin{aligned}
R_{32}^{\prime}= & \frac{R_{11}}{d_{s 13} d_{r 12}}+\frac{R_{21}}{d_{s 23} d_{r 12}}+\frac{R_{31}}{d_{r 12}} \\
& +\frac{R_{32}}{d_{s 33}}+\frac{R_{42}}{d_{s 34}}+\frac{R_{52}}{d_{s 35}}
\end{aligned}
$$

Note that reinforcers were not delivered for either response following $\mathrm{S}_{3}$, hence $R_{31}=R_{32}$ $=0$; and that there can be no discriminability between a stimulus and itself, hence $d_{s 33}=1$. The $\log$ effective reinforcer ratio (e.g., $\left(\mathrm{R}^{\prime}{ }_{31} /\right.$ $\mathrm{R}_{32}^{\prime}$ )) obtained in the current and previous three sessions was used to predict the response ratio following each stimulus in each session of the three PRTS exposures. The effect of each session's effective reinforcer ratio on the current session's response ratio was assumed to be additive as in Experiment 1. Therefore, fits of Equation 5 to the data of Experiment 2 required estimation of four stimulus-discriminability and four contingency-discriminability parameters, as well as an inherent bias term $(\log c)$.

Figure 7 shows lag contingency discriminability estimates obtained from fits of Equation 5 for each rat and PRTS. Overall, contingency

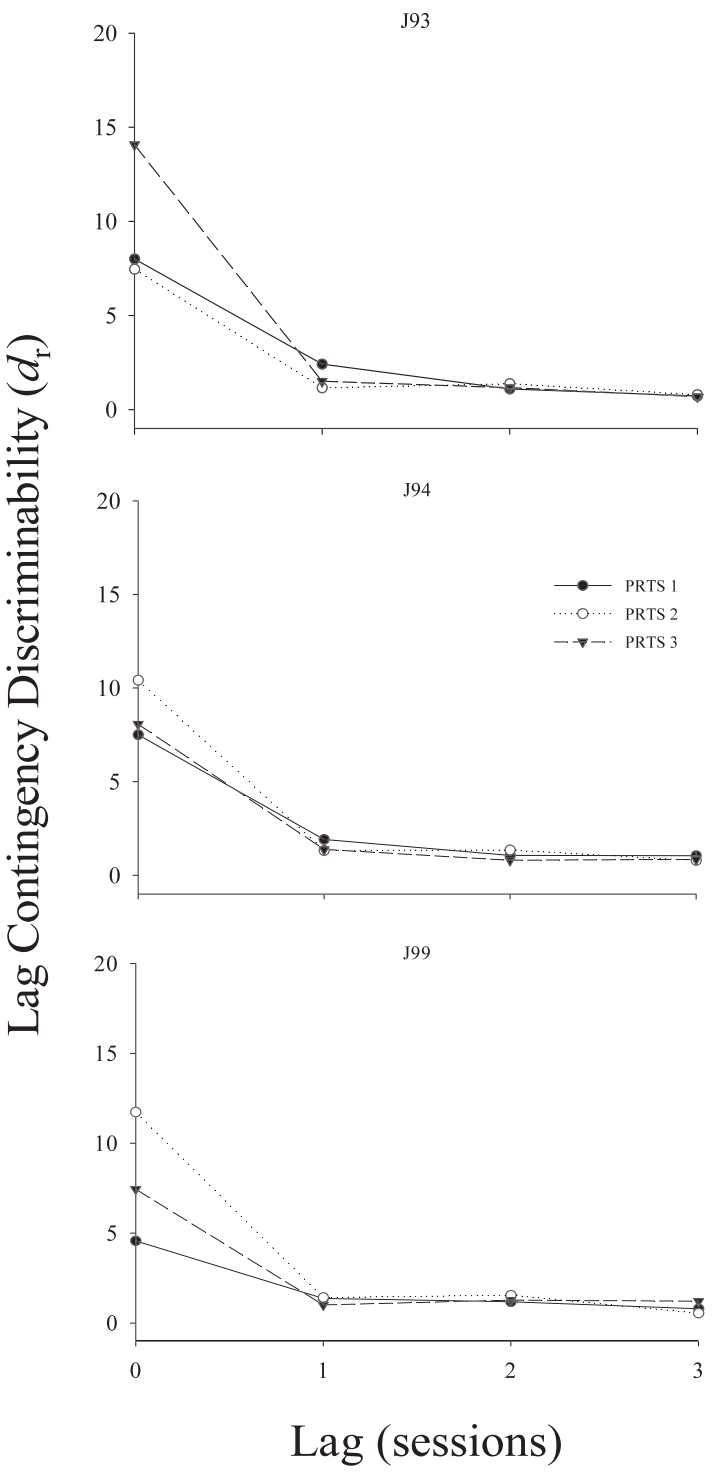

Fig. 7. Contingency discriminability $d_{\mathrm{r}}$ estimates based upon the current and previous session reinforcer ratios for each PRTS presentation of Experiment 2. The legend indicates the PRTS presentation from which the $\mathrm{d}_{r}$ estimate was obtained. The dotted lines give the lower limit of the parameter value.

discriminability was highest at lag 0 and near 1.0 at greater lags. For J94 and J99, lag 0 contingency discriminability increased from the first and second PRTS exposures and then decreased on the final PRTS to levels similar to the first exposure. For J93, little change in lag 0 contingency discriminability occurred between the first two PRTS exposures; however, a small change in lag 1 contingency discriminability is 
apparent. For this rat, lag 0 contingency discriminability increased to high levels on the third PRTS exposure for this rat. Therefore, the data from Experiment 2 conform to previous studies employing the PRBS design showing that increases in control by the current session's reinforcer ratio tend to occur following the first exposure to the sequence (Schofield \& Davison, 1997; Grace, Bragason, \& McLean, 2003).

To examine within-session changes in contingency discriminability as in Experiment 1, the data from each session of the third PRTS exposure of Experiment 2 were divided into fifths (or eight presentations of each stimulus). Because aggregating the data in this way may frequently lead to exclusive preference for a response alternative, we fitted a proportional version of the DNA model to the session fifth data (see Davison \& McCarthy, 1989). If all parameters were allowed to vary freely for each session fifth, the fits would require estimating seven parameters for each session fifth: four stimulus discriminability $\left(d_{\mathrm{sij}}\right)$, an inherent bias term $(\log c)$, and a contingency discriminability parameter $\left(d_{\mathrm{r}(\mathrm{n}-\mathrm{i})}\right)$ measuring the effect of reinforcer frequency ratios from lags 0 and 1, for a total of 35 parameters. Because the sample stimuli were the same durations throughout the experiment, estimates of stimulus discriminability should not vary with any potential within-session changes in bias. Inherent bias, measured by $\log \mathrm{c}$, should also remain constant across sessions. Thus, the stimulus discriminability and inherent bias parameters were constrained to have the same value for each session fifth (eliminating 20 parameters). Thus, the within-session analysis required that 15 parameters be estimated to predict 900 data values per individual rat. An effective reinforcer frequency was calculated for each response alternative and session fifth as in Equations 6 and 7 above. The effective reinforcer frequencies from the current and previous session were multiplied to give an overall effective reinforcer term. Therefore, using Equations 6 and 7 to obtain effective reinforcer frequencies for each response following each stimulus, the effective reinforcer terms for the current and previous session were concatenated:

$$
R^{\prime \prime}{ }_{i j}=\prod_{k=0}^{n} R_{(k) i j}
$$

where $R^{\prime \prime}{ }_{i j}$ is the overall effective reinforcer frequency including any effect of past reinforcers and $k$ is the session lag. Then, effective reinforcer terms were used to predict relative response frequency following each stimulus

$$
\left(\frac{B_{i 1}}{B_{i 1}+B_{i 2}}\right)=\left(\frac{c R^{\prime \prime}{ }_{i 1}}{c R^{\prime \prime}{ }_{i 1}+R^{\prime \prime}{ }_{i 2}}\right)
$$

where $c$ is again an overall bias towards a response alternative. Equation 9 therefore assumes that response allocation strictly matches the relative effective reinforcer frequency, which is a function of current and past contingencies of reinforcement. In the analyses reported here, only the current and immediately preceding sessions' effective reinforcer ratios were used to predict within-session adjustment (i.e., in Eq.8 $n=1)$. As in Experiment 1, a contingency discriminability estimate of 1.0 means that the relative frequency of reinforcement from the current or a previous session cannot produce a bias towards a particular response alternative. This model was fitted to individual subject data so as to minimize the residual sum of squares between the obtained and predicted response proportions of all stimulus presentations and within each session block.

Figure 8 shows the within-session changes in contingency discriminability for each rat from the third PRTS exposure. An effect of the previous session's reinforcer ratio is evident in the first block of trials for each rat. The influence of previous sessions' reinforcer ratios decreased gradually across the session. For each rat, lag 0 contingency discriminability increases within the session and appears somewhat stable in the final two blocks of trials. Therefore, Figure 8 demonstrates that response allocation moves from near indifference to relatively stable preference for the higher reinforcer frequency alternative about midway through a session or following approximately 20 presentations of each stimulus. As in Experiment 1, the model used to assess within-session changes in contingency discriminability provided an adequate fit to the session fifth data. The average percentage of variance accounted for was modest (mean VAC $=73 \%)$. Regressions performed on obtained versus predicted performance, however, revealed no systematic deviations.

Figure 9 shows psychometric functions obtained for each rat from the present experiment. 


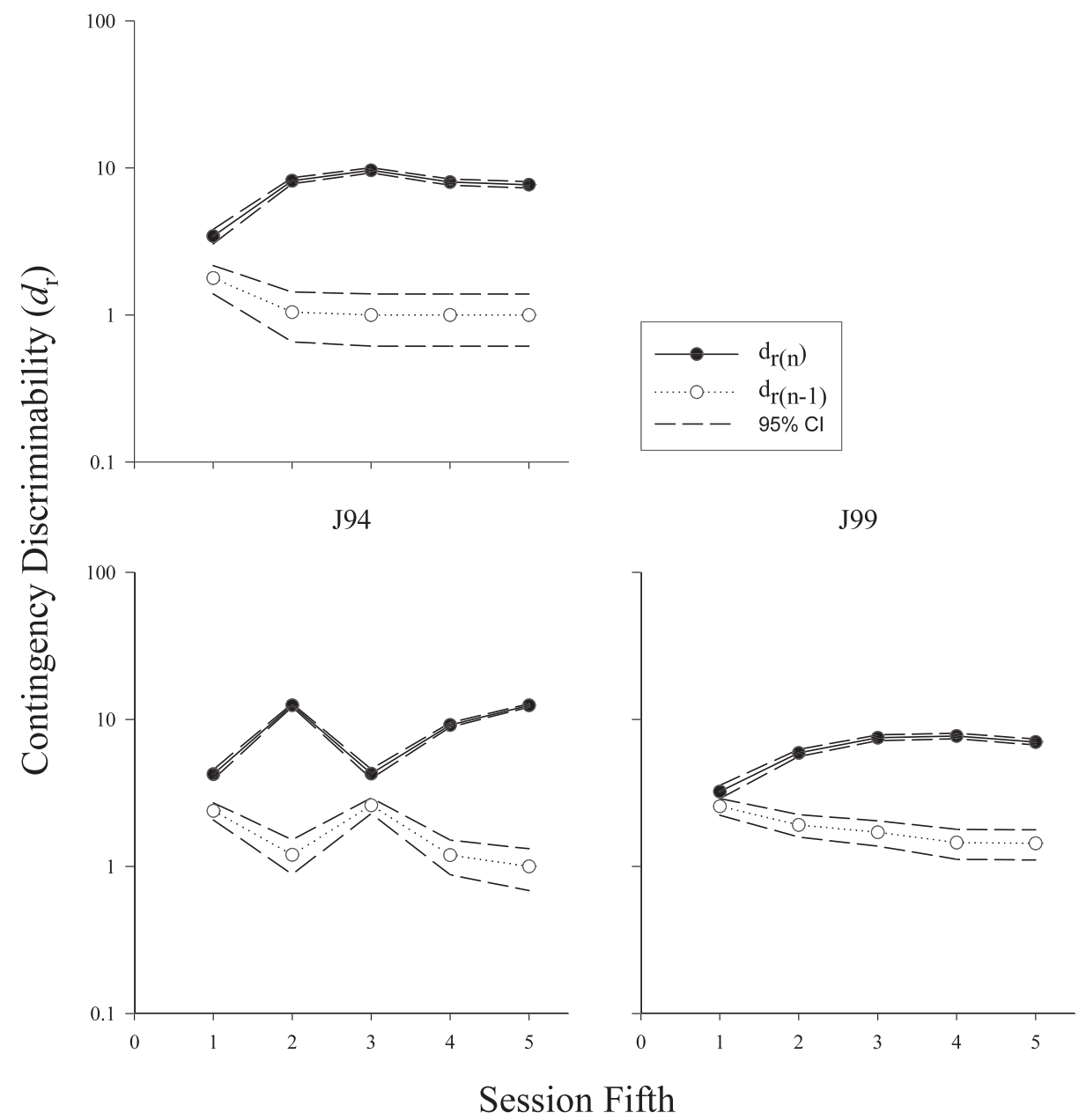

Fig. 8. Contingency discriminability $d_{\mathrm{r}}$ obtained for lags 0 through 3 obtained for each session fifth (40 trials). Data are from the third PRTS presentation of Experiment 2.

The data were taken from the last two session fifths (see Figure 8) of the final PRTS because performance had reached a steady state by this point within an experimental session. The proportions of "long" or left responses following each sample stimulus were averaged across sessions and grouped according to programmed reinforcer ratio. Figure 9 demonstrates that the proportion of responses to the left lever, indicating a long classification, increased as an ogival function of the preceding sample stimulus duration. Furthermore, each psychometric function shifted along the y-axis in accord with the programmed reinforcer probabilities. Therefore, Figure 9 affirms that the data obtained from the present method of varying reinforcer frequency produces reliable psychometric functions and the shift in each curve produced by varying the relative frequency of reinforcement for correct responses is similar to that observed in traditional steady-state procedures (Bizo \& White, 1995; Davison \& McCarthy, 1989).

As a further check on the adequacy of the extension of the DNA model used here to characterize within-session adjustments to a frequently varying reinforcer ratio we assessed the model's fit to the psychometric functions obtained from the final two session fifths (displayed in Figure 9). The models' predictions for the last two blocks of trials (trials 161-200) were averaged in the same manner as the obtained data. Table 1 gives the parameters of the DNA 


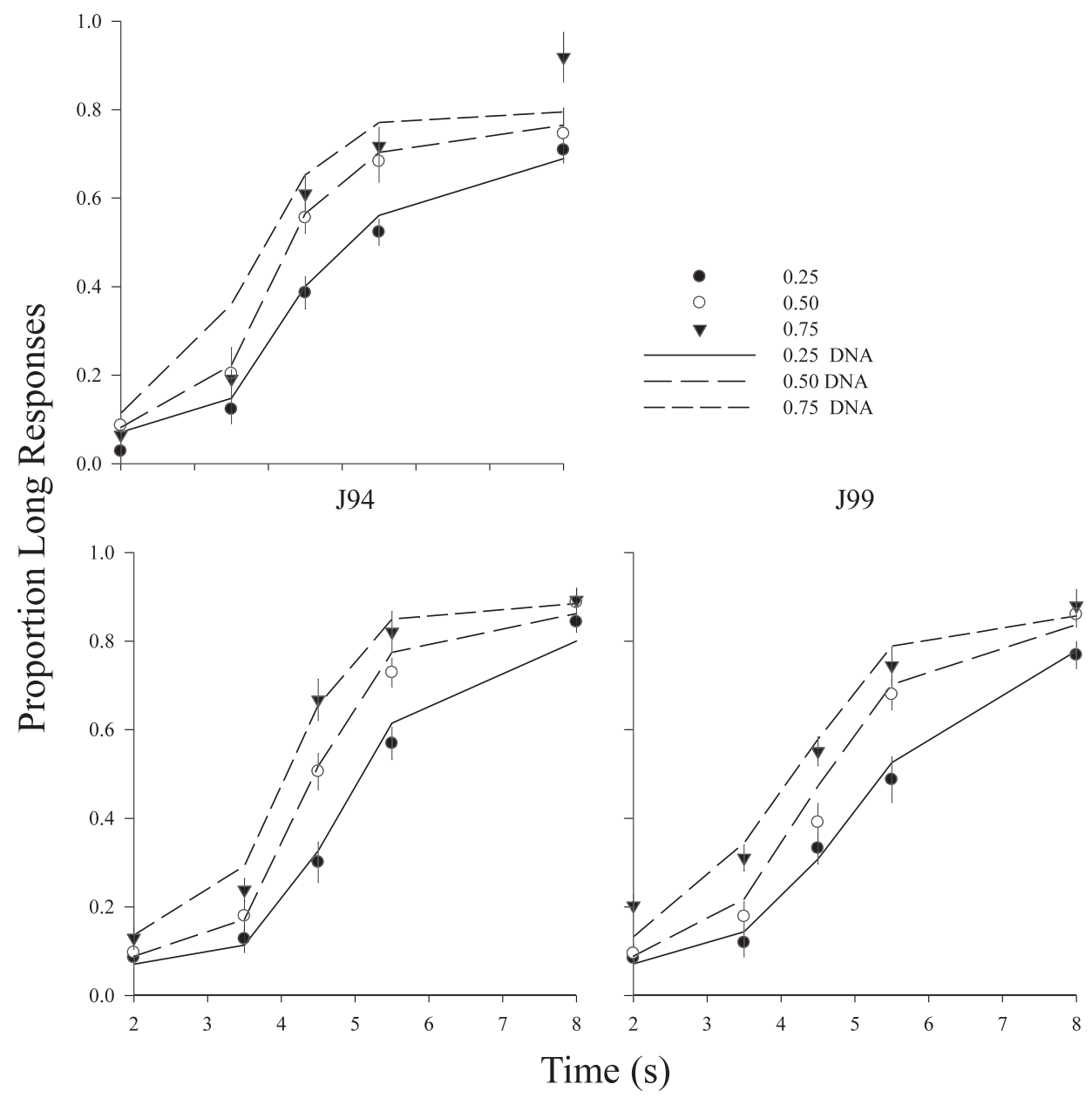

Fig. 9. Psychometric functions based on the data from the last two trial blocks of each session from the third PRTS. The proportion of long responses following each stimulus duration is plotted separately for each programmed reinforcer probability as indicated in the legend. Vertical bars represent standard error.

model along with goodness of fit indices for the data from blocks 4 and 5, aggregated across the third PRTS. As might be expected based on previous studies (Davison \& McCarthy, 1989), the fits of the DNA model to the end-of-session data, incorporating carryover from the previous session's reinforcer ratio, were excellent. Therefore, the assumption of constant stimulus discriminabilities and freely varying contingency discriminability parameters to accommodate within-session changes in bias provided an accurate description of the individual subject data.

Finally, we sought a measure of response allocation following each sample stimulus presentation that characterizes the changing response allocations as a function of successive sample presentations. We chose cumulative response proportion as a measure of preference because this measure naturally smoothes the data, making aggregation across blocks of trials unnecessary (for discussion see Gallistel et al., 2007). Data from the third PRTS were used for these analyses and response totals were summed across each session by order of stimulus presentation. That is, we plotted the cumulative relative response frequency as a function of successive presentations of a particular sample stimulus. The cumulative proportions of $\mathrm{B}_{2}$ choices $(p)$ for each rat were then converted to a $\operatorname{logit} p(\operatorname{logit} p=\log (p /(1-p))$. 
Table 1

Parameter estimates from fits of the DNA model to the data shown in Figure 9. Estimates of contingency and stimulus contingency discriminability, inherent bias, and percent variance accounted for are shown for each subject. The slope $m$ and y-intercept $b$ from regressions performed on the obtained versus predicted response proportions are also displayed. See text for further explanation.

\begin{tabular}{lrrr}
\hline & $\mathrm{J} 93$ & $\mathrm{~J} 94$ & $\mathrm{~J} 99$ \\
\hline \hline $\boldsymbol{d}_{\boldsymbol{s 1 2}}$ & 1.0 & 1.0 & 1.0 \\
$\boldsymbol{d}_{\boldsymbol{s} 23}$ & 14.8 & 8.7 & 5.6 \\
$\boldsymbol{d}_{\boldsymbol{s} 34}$ & 3.0 & 4.4 & 2.6 \\
$\boldsymbol{d}_{\boldsymbol{s 4 5}}$ & 29.2 & 38.5 & 36.8 \\
$\boldsymbol{c}$ & 0.5 & 0.8 & 0.7 \\
$\boldsymbol{d}_{\boldsymbol{r}(\boldsymbol{n})}$ & 7.8 & 10.8 & 7.4 \\
$\boldsymbol{d}_{\boldsymbol{r}(\boldsymbol{n}-\boldsymbol{1})}$ & 1.0 & 1.1 & 1.4 \\
$\mathbf{M S E}$ & 0.082 & 0.095 & 0.076 \\
$\mathbf{R}^{\mathbf{2}}$ & 0.954 & 0.992 & 0.981 \\
$\mathbf{m}$ & 1.06 & 1.00 & 0.98 \\
$\mathbf{b}$ & -0.05 & 0.00 & 0.00 \\
\hline
\end{tabular}

The cumulative choice proportion plots showed changes in preference within experimental sessions that were similar to those reported in other studies employing similar procedures (Krägeloh \& Davison, 2003; Krägeloh, Elliffe, \& Davison, 2006). For present purposes, however, we focus on cumulative response allocation following sample $\mathrm{S}_{3}$. Figure 10 shows the cumulative choice proportion plotted as a function of successive presentations of $S_{3}$ for each reinforcer frequency ratio arranged in Experiment 2. Figure 10 shows that a preference for the higher reinforcer frequency alternative emerged within 10 presentations of $S_{3}$ or approximately the first 40 trials of a session. A relatively large degree of variability in response allocation in the first few trials is evident for each rat as expected. Recall that responding following $\mathrm{S}_{3}$ never produced a food presentation yet choice is governed by the overall reinforcer frequency ratio. Figure 10 therefore suggests a fairly rapid local process by which effective reinforcer allocation operates on response allocation.

\section{GENERAL DISCUSSION}

The present research demonstrates that response bias in both simple and more complex signal detection tasks can adjust rapidly to frequent, pseudorandom changes in the reinforcer frequency ratio. The goals of the present work were to (1) explore the speed and extent of changes in bias when reinforcer ratios change frequently, (2) compare changes in bias in simple two-stimulus detection with bias in a more complex five-stimulus classification procedure, and (3) compare these findings to traditional steady state procedures.

In Experiment 1, bias changed rapidly when the reinforcer frequency ratio for correct choices changed randomly between sessions. The effect of current and previous sessions' reinforcer ratios were quantified by extending the DNA model of detection performance. Specifically, the effect of the current and previous three sessions' log effective reinforcer ratios were assumed to have an additive effect on current session performance. The additive model provided a good description of the present results. By the end of the first PRBS exposure, response bias, as assessed by contingency discriminability $d_{\mathrm{r}}$, was highest for the current session and showed little effect of the previous sessions' reinforcer ratios. This finding indicates that response bias was under control of the reinforcer ratio obtained in a given experimental session and that the extent of bias observed in Experiment 1 was obtained within a single session.

In the second PRBS presentation the $S_{1}$ and $\mathrm{S}_{2}$ stimulus durations were made more similar and discriminability, measured as $\log D$, decreased (Figure 2). Under lower levels of discrimination accuracy, variation of the reinforcer ratio had little effect on bias. The lesser degree of response bias obtained in the second PRBS presentation may be attributed to the lack of within-session control by the current session reinforcer ratio as observed in estimates of contingency discriminability within sessions (Figure 6). The DNA detection model incorporating previous sessions' effective reinforcer ratios provided an accurate account of the degree of carryover from previous sessions (Figure 4). Collectively these two analyses suggest that within- session control by the current session reinforcer ratio was often greatest at the beginning of a session and decreased thereafter.

It is unclear why contingency discriminability decreased in Experiment 1 when the sample stimulus difference was decreased making discrimination more difficult. The more typical finding in studies of detection performance is that contingency discriminability is either constant or increases when stimulus difference (measured as discriminability) decreases (for a 


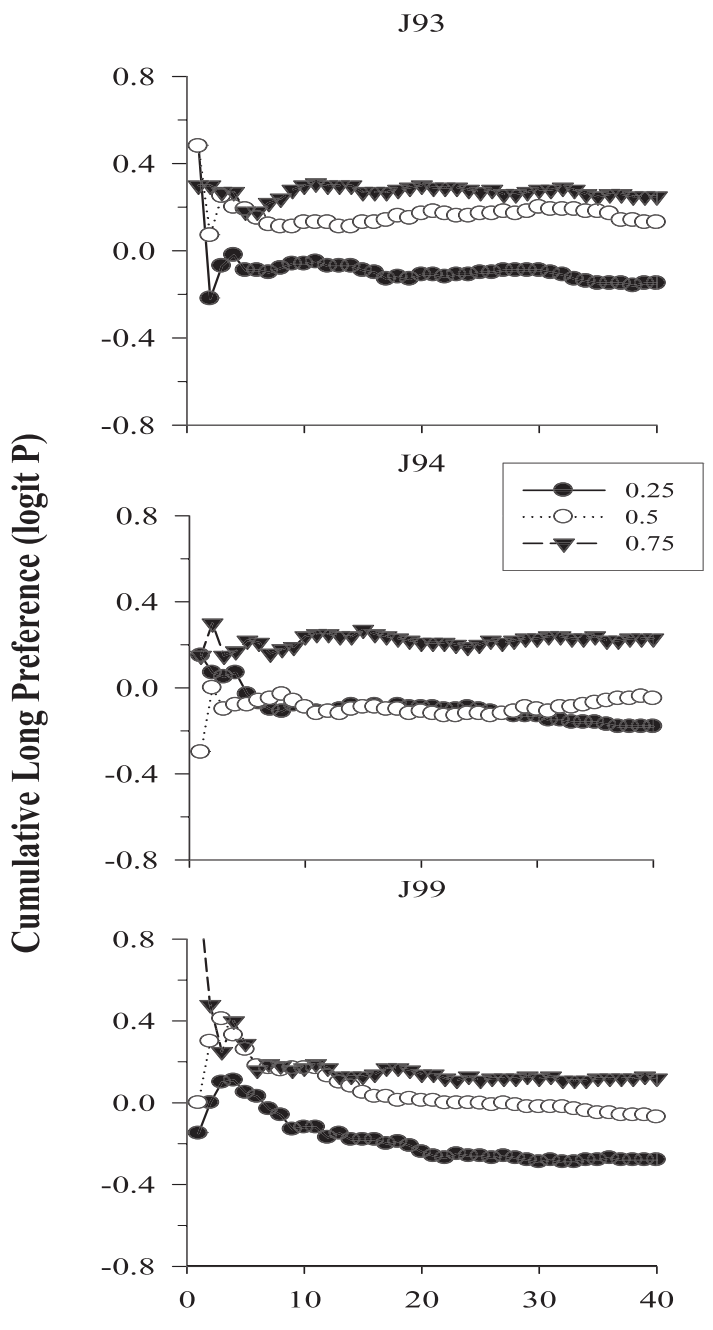

Successive Stimulus Presentations

Fig. 10. The logarithm (base 10) of the cumulative response proportion (percent long) following $S_{3}$ plotted as a function of successive presentations of $\mathrm{S}_{3}$. Data are aggregated across each session of a given reinforcer ratio (indicated in the legend) from the third PRTS of Experiment 2.

review see Alsop \& Porritt, 2006). It might be argued that the decrease in contingency discriminability observed here is the result of the use of a PRBS procedure to vary relative reinforcer frequency, per se. Results of previous studies employing temporal sample stimuli indicate, however, that the effect observed in Experiment 1 may have generality outside the use of a PRBS procedure.

McCarthy and Davison (1980) conducted a study similar to the present one in which stimulus presentations of different durations served as samples in a two-stimulus, tworesponse detection procedure. McCarthy and Davison (1980) varied the reinforcer ratio for correct responses across two levels of stimulus duration difference: 5- vs. 30-s center key illumination and 20- vs. 30-s. As expected, discrimination accuracy was higher in the first condition; however, sensitivity to reinforcement, as estimated from the Davison \& Tustin (1978) detection model, was also higher in the first condition. Because McCarthy and Davison (1980) analyzed their data according to a detection model based on the generalized matching law, a more direct comparison of their results with ours might be achieved by a reanalysis of their data according to Equations 1 and 2.

We reanalyzed McCarthy and Davison's (1980) data with the DNA detection model and found a pattern of parameter covariation (not shown) strikingly similar to the one found here. According to our reanalysis, estimates of contingency discriminability for each bird in McCarthy and Davison's (1980) study decreased in the second set of conditions when the difference between $S_{1}$ and $S_{2}$ decreased and thus lower estimates of stimulus discriminability were obtained. Therefore, a reanalysis of archival data demonstrates that the direct relation between contingency and stimulus discriminability obtained in Experiment 1 is not a product of using the PRBS procedure, but may instead be due to the use of temporal stimuli.

The finding of a direct relation between measures of control by stimulus $\left(d_{\mathrm{s}}\right)$ and reinforcement $\left(d_{\mathrm{r}}\right)$ variables in the present study underscores the need for more research using the rapid acquisition or pseudorandom sequence methodologies in the domain of signal detection. It is clear that in many situations measures of bias and discrimination covary (Alsop \& Davison, 1991; Alsop \& Porritt, 2006; Johnstone \& Alsop, 1999; McCarthy \& Davison, 1984; 1986). Although the DNA model of detection performance was proposed to address this very issue (Alsop, 1991; Davison, 1991), clearly there are some cases in which the model does not provide independent measures of control by stimulus and reinforcer variables (Alsop \& Davison, 1991; Nevin, Cate, \& Alsop, 1993; but see Nevin, Davison, \& Shahan, 2005). Perhaps a better understanding of conditional stimulus control awaits a thoroughly dynamic 
characterization of the learning that takes place in such procedures (Luce, 1964).

Finally, the differences in bias at the session aggregate level, as assessed by $d_{\mathrm{r}}$, between different PRBS exposures in Experiment 1 were consistent with changes in bias within experimental sessions. When the difference between $S_{1}$ and $\mathrm{S}_{2}$ was large, within-session estimates of contingency discriminability increased within the first session fifth and little effect of previous sessions' reinforcer ratios were evident (Figure 5). When $\mathrm{S}_{1}$ and $\mathrm{S}_{2}$ were less discriminable, however, within-session changes in lag 0 contingency discriminability were much lower than when $S_{1}$ and $S_{2}$ were more discriminable (Figure 6). For 3 of 4 rats, estimates of lag 1 contingency discriminability increased within each session and were sometimes higher than lag $0 d_{\mathrm{r}}$ by the end of a session.

We explored this finding further by plotting the cumulative number of $\mathrm{B}_{1}$ responses as a function of the cumulative number of $\mathrm{B}_{2}$ responses (Gallistel, Mark, King, \& Latham, 2001; Kyonka \& Grace, 2008). The most prominent pattern in the cumulative response scatterplots (not shown) was an increase in bias across most of the first half of an experimental session, followed by a trend toward indifference in the second half of a session. Therefore, inspection of the raw preference data revealed a crossover pattern consistent with the parameter estimates displayed in Figure 6 indicating control by the current and previous sessions' reinforcer ratio in the second PRTS exposure of Experiment 2. We can, however, offer no further interpretation of why this occurred.

In Experiment 2, bias again changed rapidly when the reinforcer frequency ratio for correct choices changed between sessions. An extension of the DNA model that incorporated the effects of current and previous sessions' effective reinforcer ratios provided a good description of both within-session and aggregate changes in bias. Control by the current session's reinforcer ratio generally increased and the effects of the previous sessions' reinforcer ratios decreased. Within-session adjustment to the current session reinforcer ratio was most rapid between the first and second session fifths (Figure 8).

There were two notable differences between the findings of Experiments 1 and 2. First, session aggregate estimates of lag $\begin{array}{lll}0 & d_{\mathrm{r}} \text { and }\end{array}$ within-session changes in $d_{\mathrm{r}}$ were intermediate in Experiment 2 relative to that observed in the two conditions of Experiment 1. The reason may be that although the same sample durations were employed in each experiment, an identification task was used in Experiment 1 and a classification task was used in Experiment 2. Godfrey and Davison (1999) showed that the DNA model provided consistent estimates of both $d_{\mathrm{s}}$ and $d_{\mathrm{r}}$ when different sample and comparison stimuli were added and removed from a set of up to five sample and comparison stimuli in an identification task. Comparing estimates of contingency discriminability across the present experiments is difficult, however, as different subjects were used and exposures to the pseudorandom sequences were not of equal duration. Nonetheless, the differences in estimates of contingency discriminability across the present experiments may suggest an important difference between identification and classification procedures (see Nosofsky, 1986).

Secondly, the design of both experiments reported here allowed for some characterization of the spread of effect of reinforcer deliveries contingent on one correct response to all available responses. The within-session changes in bias observed in both procedures (Figures. 5, 6, \& 8) supports Davison and Nevin's (1999) contention that effective reinforcer allocation occurs locally. Focusing on the classification procedure employed in Experiment 2, changes in bias following all stimuli were observed within 40-80 trials (Figure 8) or approximately 25 reinforcer deliveries $(M d n .=12.6$ per session fifth $)$. Although the analyses presented above focused on bias following $\mathrm{S}_{3}$, response allocation following the other stimuli showed similar within-session changes. This speed of adaptation is slower than that reported by Davison and Baum (2000). This was expected, however, as the present procedure employed daily changes in the reinforcer ratio, whereas Davison and Baum's (2000) procedure employed several within-session changes.

The rapid changes in bias following each stimulus duration is thus consistent with the effective reinforcement account as response allocation following each stimulus is assumed to be affected by all reinforcer deliveries in the experimental situation (Figure 1), attenuated by stimulus and/or response distance. In sum, the present experiments provide support for the concept of effective reinforcement and its dynamic nature. Future research utilizing 
procedures like those employed here may pave the way for more comprehensive dynamic models of detection performance.

In conclusion, the present findings suggest that the pseudorandom sequence method of varying relative reinforcement variables may be extended to signal detection tasks. In a research area that has seen a large degree of quantification (Davison, 1991; Davison \& Nevin, 1999; Nevin, Davison, \& Shahan, 2005; Nevin, Davison, Odum, \& Shahan, 2007), procedures that produce high quality data and rapid determination of parameter estimates are needed. Furthermore, recent research employing procedures in which contingencies change frequently have shed some light on some of the local processes governing simple concurrent choice (Krägeloh, Davison, \& Elliffe, 2005; Landon, Davison, \& Elliffe, 2003). Perhaps with further procedural development, similar advances can be made in the study of signal detection.

\section{REFERENCES}

Alsop, B. (1991). Behavioral models of signal detection and detection models of choice. In M. L. Commons, J. A. Nevin, \& M. C. Davison (Eds.), Signal detection: Mechanisms, models, and applications (pp. 39-55) Hillsdale, NJ: Erlbaum.

Alsop, B., \& Davison, M. (1991). Effects of varying stimulus disparity and the reinforcer ratio in concurrentschedule and signal-detection procedures. Journal of the Experimental Analysis of Behavior, 56, 67-80.

Alsop, B., \& Porritt, M. (2006). Discriminability and sensitivity to reinforcer magnitude in a detection task. Journal of the Experimental Analysis of Behavior, 85, 41-56.

Baum, W. M., \& Rachlin, H. C. (1969). Choice as time allocation. Journal of the Experimental Analysis of Behavior, 12, 861-867.

Bizo, L. A., \& White, K. G. (1995). Biasing the pacemaker in the behavioral theory of timing. Journal of the Experimental Analysis of Behavior, 64, 225-235.

Blough, D. S. (1969). Generalization gradient shape and summation in steady-state tests. Journal of the Experimental Analysis of Behavior, 12, 91-104.

Catania, A. C. (1998). Learning. New Jersey: Prentice-Hall.

Davison, M. C. (1991). Stimulus discriminability, contingency discriminability, and complex stimulus control. In M. L. Commons, J. A. Nevin, \& M. C. Davison (Eds.), Signal detection: Mechanisms, models, and applications (pp. 57-78). Hillsdale, NJ: Erlbaum.

Davison, M., \& Baum, W. M. (2000). Choice in a variable environment: every reinforcer counts. Journal of the Experimental Analysis of Behavior, 74, 1-24.

Davison, M., \& Baum, W. M. (2002). Choice in a variable environment: effects of blackout duration and extinction between components. Journal of the experimental Analysis of Behavior, 77, 65-89.
Davison, M., \& Baum, W. M. (2003). Every reinforcer counts: Reinforcer magnitude and local preference. Journal of the Experimental Analysis of Behavior, 80, 95-129.

Davison, M., \& Jenkins, P. E. (1985). Stimulus discriminability, contingency discriminability, and schedule performance. Animal Learning $\mathcal{E}$ Behavior, 13, 77-84.

Davison, M., \& McCarthy, D. (1988). The matching law: A research review. Hillsdale, NJ: Erlbaum.

Davison, M., \& McCarthy, D. (1989). Effects of relative reinforcer frequency on complex color detection. Journal of the Experimental Analysis of Behavior, 51, 291-315.

Davison, M., \& Nevin, J. A. (1999). Stimuli, reinforcers, and behavior: An integration. Journal of the Experimental Analysis of Behavior, 71, 439-482.

Davison, M. C., \& Tustin, R. D. (1978). The relation between the generalized matching law and signaldetection theory. Journal of the Experimental Analysis of Behavior, 29, 331-336.

Egan, J. P. (1975). Signal detection theory and ROC analysis. New York: Academic Press.

Gallistel, C. R., Mark, T. A., King, A. P., \& Latham, P. (2001). The rat approximates an ideal detector of changes in rates of reward: Implications for the law of effect. Journal of Experimental Psychology: Animal Behavior Processes, 27, 354-372.

Gallistel, C. R., King, A. P., Gottlieb, D., Balci, F., Papachristos, E. B., Szalecki, M., \& Carbone, K. S. (2007). Is matching innate? Journal of the Experimental Analysis of Behavior, 87, 161-199.

Godfrey, R., \& Davison, M. (1999). The effects of number of sample stimuli and number of choices in a detection task on measures of discriminability. Journal of the Experimental Analysis of Behavior, 72, 33-55.

Grace, R. C. (1994). A contextual model of concurrent chains choice. Journal of the Experimental Analysis of Behavior, 61, 113-129.

Grace, R. C., Bragason, O., \& McLean, A. P. (2003). Rapid acquisition of preference in concurrent chains. Journal of the Experimental Analysis of Behavior, 80, 235-252.

Grace, R. C., \& McLean, A. P. (2006). Rapid acquisition in concurrent chains: Evidence for a decision model. Journal of the Experimental Analysis of Behavior, 85, 181-202.

Green, D. M., \& Swets, J. (1966). Signal detection theory and psychophysics. New York: Wiley.

Hunter, I., \& Davison, M. (1985). Determination of a behavioral transfer function: White-noise analysis of session-to-session response-ratio dynamics on concurrent VI VI schedules. Journal of the Experimental Analysis of Behavior, 43, 43-59.

Johnstone, V., \& Alsop, B. (1999). Stimulus presentation ratios and the outcomes for correct responses in signal-detection procedures. Journal of the Experimental Analysis of Behavior, 72, 1-20.

Killeen, P. (1972). The matching law. Journal of the Experimental Analysis of Behavior, 17, 489-495.

Krägeloh, C. U., \& Davison, M. (2003). Concurrentschedule performance in transition: changeover delays and signaled reinforcer ratios. Journal of the Experimental Analysis of Behavior, 79, 87-109.

Krägeloh, C. U., Davison, M., \& Elliffe, D. M. (2005). Local preference in concurrent schedules: The effects of reinforcer sequences. Journal of the Experimental Analysis of Behavior, 84, 37-64. 
Krägeloh, C. U., Elliffe, D. M., \& Davison, M. (2006). Contingency discriminability and peak shift in concurrent schedules. Journal of the Experimental Analysis of Behavior, 86, 11-30.

Kyonka, E. G. E., \& Grace, R. C. (2008). Rapid acquisition of preference in concurrent chains when alternatives differ on multiple dimensions of reinforcement. Journal of the Experimental Analysis of Behavior, 89, 49-69.

Landon, J., Davison, M., \& Elliffe, D. (2003). Choice in a variable environment: Effects of unequal reinforcer distributions. Journal of the Experimental Analysis of Behavior, 80, 187-204.

Luce, R. D. (1963). Detection and recognition. In R. D. Luce, R. R. Bush, \& E. Galanter (Eds.), Handbook of Mathematical Psychology (Vol. 1, pp. 103-190). New York: Wiley.

Luce, R. D. (1964). Asymptotic learning in psychophysical theories. British Journal of Statistical Psychology, 17, 1-14.

Macmillan, N. A., \& Creelman, C. D. (1991). Detection theory: A user's guide. Cambridge, England: Cambridge University Press.

Mazur, J. E. (1992). Choice behavior in transition: Development of preference with ratio and interval schedules. Journal of Experimental Psychology: Animal Behavior Processes, 18, 364-378.

Mazur, J. E. (1995). Development of preference and spontaneous recovery in choice behavior with concurrent variable-interval schedules. Animal Learning and Behavior, 23, 93-103.

Mazur, J. E. (2001). Hyperbolic value addition and general models of animal choice. Psychological Review, 108, 96-112.

McCarthy, D., \& Davison, M. (1980). Independence of sensitivity to relative reinforcement rate and discriminability in signal detection. Journal of the Experimental Analysis of Behavior, 34, 273-284.

McCarthy, D., \& Davison, M. (1984). Isobias and alloiobias in animal psychophysics. Journal of Experimental Psychology: Animal Behavior Processes, 10, 390-409.
McCarthy, D., \& Davison, M. (1986). On the discriminability of fixed- from variable-stimulus durations. Journal of Experimental Psychology: Animal Behavior Processes, 12, 48-58.

Nevin, J. A., Cate, H., \& Alsop, B. (1993). Effects of differences between stimuli, responses, and reinforcer rates on conditional discrimination performance. Journal of the Experimental Analysis of Behavior, 59, 147-161.

Nevin, J. A., Davison, M., Odum, A. L., \& Shahan, T. A. (2007). A theory of attending, remembering, and reinforcement in delayed matching to sample. Journal of the Experimental Analysis of Behavior, 88, 285-317.

Nevin, J. A., Davison, M., \& Shahan, T. A. (2005). A theory of attending and reinforcement in conditional discriminations. Journal of the Experimental Analysis of Behavior, 84, 281-303.

Nosofsky, R. M. (1986). Attention, similarity, and the identification-categorization relationship. Journal of Experimental Psychology: General, 115, 39-57.

Rachlin, H. (1971). On the tautology of the matching law. Journal of the Experimental Analysis of Behavior, 15, 249-251.

Rachlin, H. (2006). Notes on discounting. Journal of the Experimental Analysis of Behavior, 85, 425-435.

Schofield, G., \& Davison, M. (1997). Nonstable concurrent choice in pigeons. Journal of the Experimental Analysis of Behavior, 68, 219-232.

Shahan, T. A., Podlesnik, C. A., \& Jimenez-Gomez, C. (2006). Matching and conditioned reinforcement rate. Journal of the Experimental Analysis of Behavior, $85,167-180$.

Stubbs, D., \& Pliskoff, S. S. (1969). Concurrent responding with fixed relative rate of reinforcement. Journal of the Experimental Analysis of Behavior, 12, 887-895.

Received: April 22, 2010

Final Acceptance: September 20, 2011 